\title{
Application of Cardiac Impedance Signal in the Reservoir-Wave Model of Circulatory System in Humans
}

\author{
Marek Żyliński ${ }^{1}$, Wiktor Niewiadomski ${ }^{2}$, Marta Sadowiec ${ }^{1}$, Marcel Młyńczak ${ }^{1}$, Gerard Cybulski $^{1}$ \\ 1. Institute of Metrology and Biomedical Engineering, Faculty of Mechatronics, \\ Warsaw University of Technology, Poland \\ 2. Mossakowski Medical Research Centre, Polish Academy of Sciences, Warsaw, Poland
}

\begin{abstract}
Reservoir-wave model assumes that aortic blood pressure curve $\left(P_{a o}(t)\right)$ is a sum of two pressure components: first related to change in the blood volume within aorta $\left(P_{w k}(t)\right)$, second related to axial velocity of blood along the aorta $\left(P_{e x}(t)\right)$.

If impedance cardiography (ICG) signal tracks changes of blood volume within segment of thorax, it can be used to estimate $P_{w k}(t)$ noninvasively in humans. During late diastole, according to reservoir-wave model $P_{a o}(t)=P_{w k}(t)$. Moreover, $P_{w k}(t)$ in aorta and pressure in peripheral arteries should be similar. If these assumptions hold true, during late diastole, shapes of $P_{a o}(t)$, of pressure in peripheral arteries, and of impedance cardiography signal should be exponential decay curves with the same time constant.

Parameters of exponential decay curves of radial pressure obtained with Finapres and of cardiac impedance were compared in 4 subjects. Different locations of ICG sensing electrodes were tested

We found that degree of similarity between ICG and Finapres signals depends on the location of ICG sensing electrodes. Motion artifacts and $O$ wave distorted ICG curves and diminished the similarity between the two curves. Least effected and most similar to decaying portion of radial pressure curve was the impedance signal obtained with sensing electrodes localized upon the abdominal aorta, but the shape of two signals still considerably varied. Thus, we conclude that impedance signal can be used to determine the parameters of $P_{w k}(t)$ curve in humans only if essential improvement in gaining and processing of this signal will be applied.
\end{abstract}

\section{Introduction}

Time courses of axial aortic blood flow and aortic pressure are different. This phenomenon is the centerpiece of the reservoir-wave model of circulation system [1], which can be viewed as the modification of.
Westerhof's three-element model [2]. Reservoir-wave model assumes that aortic blood pressure curve $\mathrm{P}_{\text {ao }}(\mathrm{t})$ is a sum of two pressure components: $P_{w k}(t)$ - related to change in the blood volume within the aorta and $\mathrm{P}_{\mathrm{ex}}(\mathrm{t})$ related to the velocity of axial blood flow in the aorta:

$$
P_{a o}(t)=P_{e x}(t)+P_{w k}(t)
$$

The shape of $P_{\mathrm{ex}}(\mathrm{t})$ curve is the same as $\mathrm{v}(\mathrm{t})$-blood axial velocity time course. The ratio $P_{e x}(t) / v(t)$ is almost constant in time and equals $\mathrm{Z}_{0}$-characteristic impedance of aorta.

Time course of $\mathrm{P}_{\mathrm{wk}}(\mathrm{t})$ is predicted by two elements Windkessel model proposed by Otto Frank [3] (resistance and capacity connected in parallel). During ejection period of cardiac cycle, blood flow into arterial tree exceeds blood outflow into resistance vessels resulting in the increase of blood volume within arteries and in consequence in rise of $\mathrm{P}_{\mathrm{wk}}$. During post-ejection period blood inflow ceases but blood outflow continues, thus causing blood volume within arteries as well as arterial pressure to decline exponentially. At this time $\mathrm{P}_{\mathrm{ao}}(\mathrm{t})$ equals $\mathrm{P}_{\mathrm{wk}}(\mathrm{t})$ and can by describe as:

where:

$$
\Delta P_{w k}(t)=P_{0} * e^{-\frac{t}{\tau_{p}}}-P_{d}
$$

$\mathrm{P}_{0}$ is pressure at end of ejection

$P_{d}$ is the end diastolic pressure

$\tau_{\mathrm{p}}$ is time constant of pressure decay.

It is assumed (in animal model) [4] that change of impedance cardiography signal $\Delta \mathrm{Z}$ reflects change of arterial blood volume $\left(\Delta \mathrm{V}_{\mathrm{wk}}(\mathrm{t})\right)$ in thoracic segment. Nyboer [5] proposed formula that derives blood volume change from cardiac impedance signal:

where:

$$
\Delta V_{w k}(t)=\rho * l_{0}^{2} * Z^{-2} * \Delta Z(t)
$$

$\rho$ is blood resistivity,

$1_{0}$ is length of segment, in which impedance was measured,

$\mathrm{Z}$ is base impedance of the segment,

$\Delta Z$ is a change of this segment's impedance.

Since $\rho$ and $l_{0}$ do not change and $Z$ depends on body posture, formula (3) can be rewritten to highlight the 
linear relation between $\Delta \mathrm{V}_{\mathrm{wk}}$ and $\Delta \mathrm{Z}$ :

$$
\Delta V_{w k}=X * \Delta \mathrm{Z}
$$

where

$$
X=\rho * l_{0}^{2} * Z^{-2}
$$

Thus the shape of $\Delta \mathrm{Z}(\mathrm{t})$ curve should be similar to the shape of $\Delta \mathrm{V}_{\mathrm{wk}}(\mathrm{t})$ and because

$$
\Delta V_{w k}(t)=\Delta P_{w k}(t) * C
$$

where $\mathrm{C}$ is arterial compliance,

the relation between $\Delta \mathrm{P}_{\mathrm{wk}}(\mathrm{t})$ and $\Delta \mathrm{Z}$ can be described as:

$$
\Delta P_{w k}(t)=\frac{\Delta \mathrm{z}(\mathrm{t}) * X}{C}
$$

one may assume that

$$
\Delta \mathrm{Z}(\mathrm{t})=Z_{0} * e^{-\frac{t}{\tau_{z}}}-Z_{d}
$$

where:

$\mathrm{Z}_{0}$ is the impedance at end of ejection

$Z_{d}$ is the impedance at the end of diastole

$\tau_{\mathrm{z}}$ is time constant of impedance decay.

The aim of this study was to find out whether the shape of $\mathrm{P}_{\mathrm{ao}}(\mathrm{t})$ during late diastole is similar to the shape of impedance cardiography signal so $\Delta \mathrm{Z}$ can by use to estimate time constant of $\mathrm{P}_{\mathrm{wk}}(\mathrm{t})$ decay.

For this to be true two conditions must be met:

- $\mathrm{X}$ value does not change in time.

- $\tau_{\mathrm{z}}$ and $\tau_{\mathrm{p}}$ must be equal

\section{Method}

\subsection{Measurement}

Four persons participated in the study. During the examination, subjects rested in supine position. Radial pressure was measured with Portapres (Finapres Medical System, Netherlands), EKG was recorded with cardiac monitor (Omron, Japan) and cardiac impedance measured with the device built by us.

For every subject, three different locations of ICG sensing electrodes were tested (Fig. 1 and Table 1) For each locations, 1 minute record was obtained.

\subsection{Signal analysis}

Signals analysis was performed with Matlab R2016B (MathWorks, USA)

Firstly, the beginning of cardiac cycle was detected as a maximum of $R$ wave in ECG signal. Detection of this point was performed with our own detection algorithm [6]. Next the beginning of blood ejection from left ventricle was detected as blood pressure and cardiac impedance signals minima following $R$ wave. Signal from last $30 \%$ of cardiac cycle was assumed to be late diastole portion.

Late diastole portion of $\Delta \mathrm{Z}$ signal was linearly fitted to late diastole radial pressure with 1st-degree polynomial fit and P1 coefficient was used as $\mathrm{X} / \mathrm{C}$ value in formula 6 .

Blood pressure was fit to model describe in formula 2 and $\Delta \mathrm{Z}$ was fit to formula 7 model. $\tau_{\mathrm{p}}$ and $\tau_{\mathrm{z}}$ value were estimate by fit function (Matlab's Curve Fitting Toolbox).

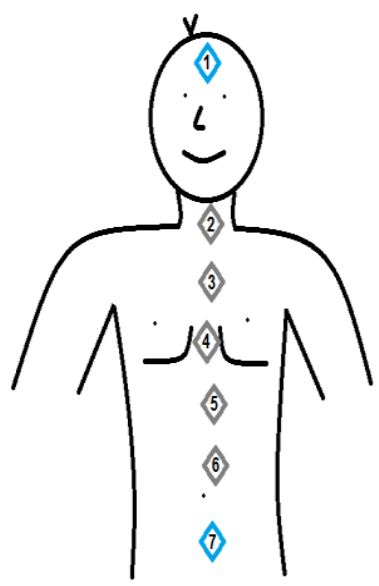

Figure 1. Position of cardiac impedance electrode

Table 1. Electrodes positions in ICG leads

\begin{tabular}{|l|c|c|c|}
\hline \multicolumn{5}{|c|}{ Patient, I lead location(33-year-old female) } \\
\hline Lead & $\begin{array}{l}\text { Position of } \\
\text { application } \\
\text { electrodes }\end{array}$ & $\begin{array}{l}\text { Position of } \\
\text { sensing } \\
\text { electrodes }\end{array}$ & $\begin{array}{l}\text { Distance between } \\
\text { sensing electrode }\end{array}$ \\
\hline I-A & $1-7$ & $2-4$ & $16 \mathrm{~cm}$ \\
\hline I-B & $1-7$ & $3-6$ & $36 \mathrm{~cm}$ \\
\hline I-C & $1-7$ & $3-5$ & $30 \mathrm{~cm}$ \\
\hline Patient II (24-years old female) & $17 \mathrm{~cm}$ \\
\hline II-A & $1-7$ & $3-5$ & $16 \mathrm{~cm}$ \\
\hline II-B & $1-7$ & $4-6$ & $15 \mathrm{~cm}$ \\
\hline II-C & $1-6$ & $2-4$ & $8 \mathrm{~cm}$ \\
\hline Patient III (25-years old male) & $15 \mathrm{~cm}$ \\
\hline III-A & $1-6$ & $2-3$ & $12 \mathrm{~cm}$ \\
\hline III-B & $1-7$ & $4-6$ & $34 \mathrm{~cm}$ \\
\hline III-C & $1-7$ & $3-5$ & $17 \mathrm{~cm}$ \\
\hline \multicolumn{4}{|l|}{ Patient IV (63-years old male) } \\
\hline IV-A & $1-7$ & $2-5$ & $25 \mathrm{~cm}$ \\
\hline IV-B & $1-7$ & $2-3$ & $3-5$ \\
\hline IV-C & $1-7$ & \multicolumn{2}{|l|}{} \\
\hline
\end{tabular}

\section{Results}

Results of signal analysis are listed in Table 2. In some leads in late diastole $\mathrm{O}$ wave appeared in cardiac impedance signal, changing decay time constant. Occurrences $(+)$ of $\mathrm{O}$ wave are listed in Table 2. Effects of motion artifacts and $\mathrm{O}$ wave in impedance signal are shown in Figure 4.

Poor fit of late diastole signal are shown in Figure 2 and good fit in Figure 3. 
Table 2. Mean values from 1 minute of $\mathrm{X} / \mathrm{C}$ and impedance and blood pressure decay time constants and theirs standard deviations, + indicates occurrence of $\mathrm{O}$ wave, - indicates absence of $\mathrm{O}$ wave.

\begin{tabular}{|c|c|c|c|c|c|c|c|}
\hline Lead & $\begin{array}{c}\text { Mean } \\
\tau_{\mathrm{p}}\end{array}$ & $\begin{array}{c}\text { Standard } \\
\text { deviation } \\
\text { of } \tau_{\mathrm{p}}\end{array}$ & $\begin{array}{c}\text { Mean } \\
\tau_{\mathrm{z}}\end{array}$ & $\begin{array}{c}\text { Standard } \\
\text { deviation } \\
\text { of } \tau_{\mathrm{z}}\end{array}$ & $\begin{array}{c}\text { Mean } \\
\text { X/C }\end{array}$ & $\begin{array}{c}\text { Standard } \\
\text { deviation } \\
\text { of X/C }\end{array}$ & $\begin{array}{c}\text { O } \\
\text { Wave }\end{array}$ \\
\hline I-A & 1,08 & 0,16 & 3,26 & 3,67 & 163,8 & 60,7 & + \\
\hline I-B & 1,24 & 0,17 & 1,47 & 0,2 & 32,4 & 6.0 & + \\
\hline I-C & 1,43 & 0,26 & 1,65 & 0,28 & 33,2 & 4,9 & - \\
\hline II-A & 1,38 & 0,26 & 1,88 & 0,59 & 107,5 & 27,2 & + \\
\hline II-B & 1,38 & 0,26 & 4,15 & 3,52 & 143,6 & 64,7 & + \\
\hline II-C & 1,39 & 0,29 & 1,74 & 0,44 & 109,5 & 28,7 & - \\
\hline III-A & 2,54 & 0,74 & 3,33 & 2,07 & 446,6 & 234,7 & - \\
\hline III-B & 2,54 & 0,74 & 4,11 & 2,59 & 298,2 & 146,7 & + \\
\hline III-C & 1,41 & 0,2 & 1,94 & 0,97 & 1352 & 523,2 & - \\
\hline IV-A & 1,31 & 0,07 & 1,8 & 0,67 & 572,6 & 130,7 & - \\
\hline IV-B & 1,42 & 0,17 & 2,92 & 2,87 & 265,1 & 194 & + \\
\hline IV-C & 1,42 & 0,17 & 1,91 & 0,86 & 550,5 & 223,8 & - \\
\hline
\end{tabular}

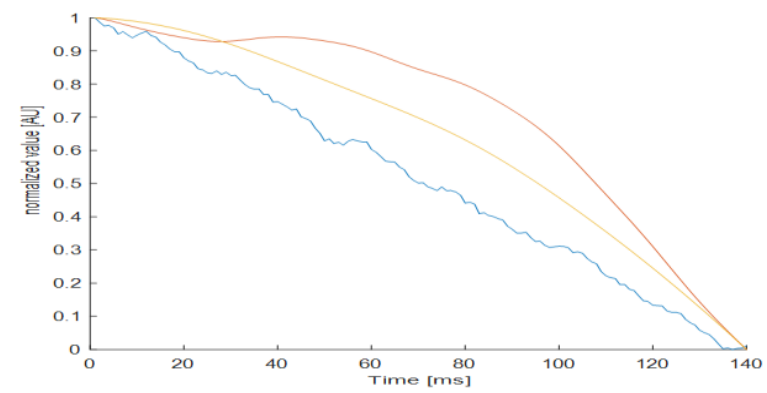

Figure 2. Example of poor fit of late diastole blood pressure (blue) with impedance signal for leads III-B (yellow) and III-C with O wave (red). Signals are averaged over all recorded cardiac cycles and normalized.

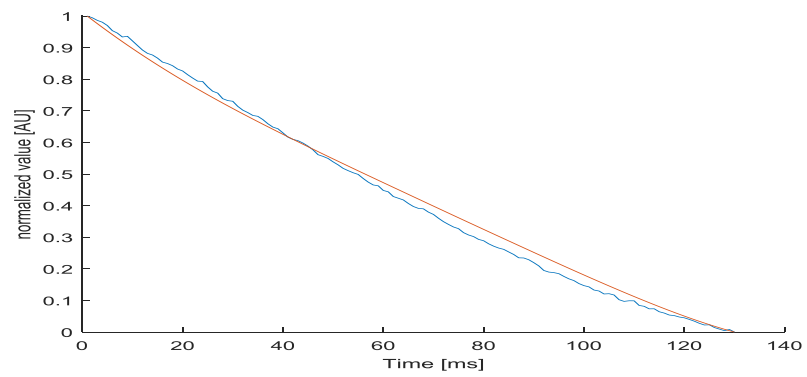

Figure 3. Example of good fit of the late diastole blood pressure (blue) and impedance signal II-C (red). Signals are averaged over all recorded cardiac cycles and normalized.
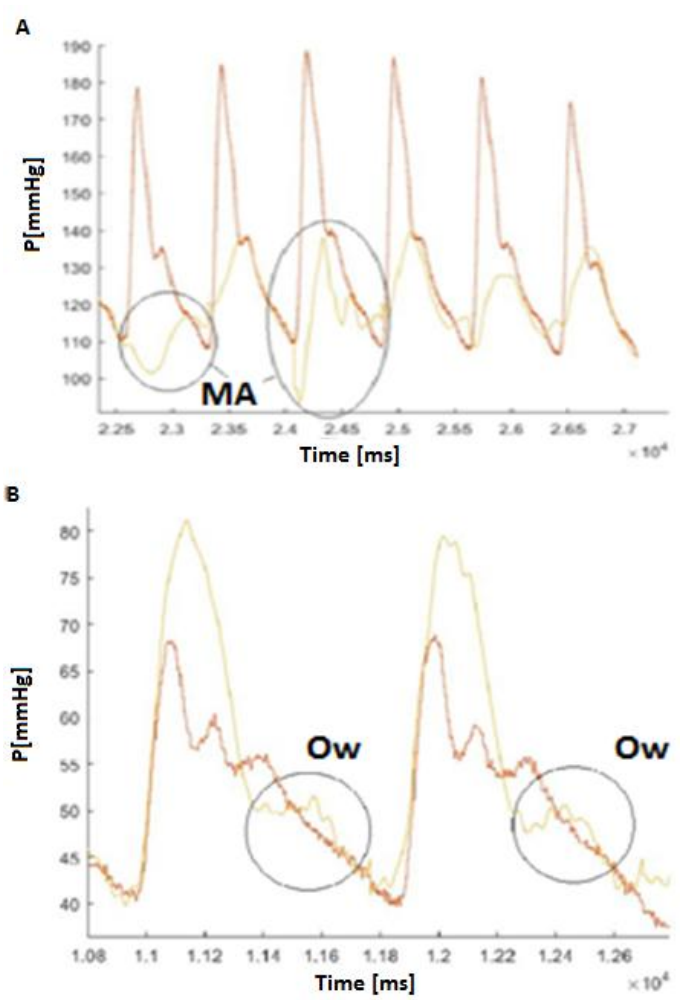

Figure 4. Cardiac impedance signals (yellow) matched with a radial pressure (red) (patient III). A (upper part): motion artifacts denoted with MA, B (bottom part) O wave of cardiac impedance signal are denoted with $\mathrm{Ow}$

\section{Discussion}

In Otto Frank model [3] decay time constant is product of total peripheral resistance $(\mathrm{R})$ and total arterial capacitance $(\mathrm{C})$ :

$$
\tau=C * R
$$

$\mathrm{C}$ falls within range of $1-2 * 10^{-3}\left[\mathrm{~cm}^{5} / \mathrm{dyn}\right]$ and $\mathrm{R}$ falls within range 1000-1400 [dyn* $\left.\mathrm{s}^{*} \mathrm{~cm}^{-5}\right]$ so value of $\tau$ can vary within physiological range of 1.0-2.8 second $[7,8]$.

Most of obtained value of $\tau_{\mathrm{p}}$ and $\tau_{\mathrm{z}}$ were within this range [Table 2]. Values of $\tau_{\mathrm{p}}$ were smaller than those of $\tau_{\mathrm{z}}$, they were equal in none of the ICG leads. In leads, where the area between sensing electrodes encompassed the abdominal aorta, shape of blood pressure curve during late diastole matched cardiac impedance signal well (Figure 3) and normalized signals almost overlap. This can suggests that shape of $\mathrm{P}_{\mathrm{ao}}(\mathrm{t})$ in late diastole can be proportional to impedance cardiography signal derived from these leads and may be used to estimate of the time course of late diastole portion of $\mathrm{P}_{\mathrm{wk}}(\mathrm{t})$.

Time constant $\tau_{\mathrm{z}}$ was overestimated in every leads wherever $\mathrm{O}$ wave appeared in impedance signal.

Siebert suggests that $\mathrm{O}$ wave is associated with an opening snap of the mitral valve [9] and may be the 
symptoms of the bicuspid valve malfunction. The shape of impedance curve during late diastole seemed to better match blood pressure signal, when neither aortic arch nor heart contributed to the signal, thus cardiac impedance leads upon the abdominal aorta should be preferred.

Cardiac impedance signal is sensitive to motion artifacts. Our study showed that this limited the usefulness of the ICG signal (Figure 4). Every motion artifact disrupted the signal and it might explain, why standard deviation of $\tau_{\mathrm{z}}$ was so much greater than that associated with $\tau_{\mathrm{p}}$. Use of an array of electrodes can reduce of occurrence of motion artifacts [10] and adaptive filters can help also to remove signal's distortion [11]. Main source of cardiac impedance signal is believed to blood volume changes but signal may also reflect changes of regional tissue impedance. The waveforms measured by an impedance cardiograph are affected not only by the change of blood volume in the aorta but also by that in various organs such as the heart and lungs. In effect the impedance measured with a pair of electrodes gathers and sums effects stemming from different sources, with the dominant contribution of those located in the vicinity of the electrodes[12].

Assumption of Otto Frank model that pressure in every segment of cardiovascular system is the same is certainly not met. The shape of pressure wave during propagation are changed and it may effected our results[13], thou, according to Wang et al. [1] it should be uniform during late diastole. This assumption should be verified by recording blood pressure or blood pressure related signals in multiple locations with help of tonometry. Central pressure can by reconstructed with transfer function $[14,15]$ using radial pressure.

Basing on preliminary results, we may conclude, that in contrary to the Wang et al. study [4], our processing of impedance signal recorded in man, did not resulted in the acceptable level of accordance in shape with arterial pressure curve, even during late diastole period. Thus, different methods of impedance signal processing leading to estimate $\mathrm{P}_{\mathrm{wk}}(\mathrm{t})$ should be investigated in order to extract from cardiac impedance signal some useful information in the context of reservoir - wave model of circulatory system.

\section{References}

[1] Wang J. J., O'Brien A. B., Shrive N. G., Parker K. H., Tyberg J. V. Time-domain representation of ventricular-arterial. Am J Physiol Heart Circ Physiol 2003; 284: H1358-H1368.

[2] Westerhof N, Noordergraaf A. Arterial viscoelasticity: a generalized model: effect on input impedance and wave travel in the systematic tree. Journal of Biomechanics 1970; 3(3):357IN15371370IN16379.
[3] Frank O. Die grundform des arteriellen pulses. Z Biol $1899 ; 37: 483-526$

[4] Wang Jr J., de Vries G, Tyberg J. V. Estimation of left ventricular stroke volume by impedance cardiography: its relation to the aortic reservoir. Experimental physiology 2013; 98(7):1213-1224.

[5] Nyboer J., Kreider, M. M, Hannapel L. Electrical impedance plethysmography. Circulation 1950 ; 2(6):811-821.

[6] Pan J, Tompkins W. J. A real-time QRS detection algorithm. IEEE transactions on biomedical engineering, 1985; 3: 230-236.

[7] Laskey W. K., Parker, H. G., Ferrari, V. A., Kussmaul, W. G, Noordergraaf A. Estimation of total systemic arterial compliance in humans. Journal of Applied Physiology, 1990; 69(1): 112-119.

[8] McVeigh, G. E., Bratteli, C. W., Morgan, D. J., Alinder C. M, Glasser S. P, Finkelstein S. M, Cohn J. $\mathrm{N}$. Age-related abnormalities in arterial compliance identified by pressure pulse contour analysis. Hypertension, 1999; 33(6): 1392-1398.

[9] Siebert J, Wtorek J.: Impedance cardiography. The early diastolic phase of heart Chambers feeling - O dZ/dt (In Polish). Ann AcadGedan 1993; 27:79-89

[10] Silke B, McAuley D. Accuracy and precision of blood pressure determination with the Finapres. $J$ Hum Hypertens, 1998; 12: 403-409.

[11] Qu M, Zhang Y, Webster J. G, Tompkins W. J. Motion artifact from spot and band electrodes during impedance cardiography. IEEE Transactions on Biomedical Engineering 1986; 11:1029-1036.

[12] Sakamoto K, Muto K, Kanai H, Iizuka M. Problems of impedance cardiography. Medical and Biological Engineering and Computing 1979;17(6): 697-709

[13] Hamilton P. S, Curley M. G, Aimi R. M, Sae-Hau C. Comparison of methods for adaptive removal of motion artifact. In Computers in Cardiology 2000 2000; 383-386

[14] Karamanoglu M. M. A. R, O'Rourke M. F, Avolio A. P, Kelly R. P. An analysis of the relationship between central aortic and peripheral upper limb pressure waves in man. European heart journal, 1993;14(2):160-167.

[15] Sharman J. E, Lim R, Qasem A. M, Coombes J. S, Burgess M. I, Franco J, Marwick T. H. Validation of a generalized transfer function to noninvasively derive central blood pressure during exercise. Hypertension, 2006; 47(6):1203-1208.

Corresponding author:

Author: Marek Żyliński

Institute: Institute of Metrology and Biomedical

Engineering, Faculty of Mechatronics

ul. Św. A. Boboli 8

02-525 Warsaw Poland

Email: zylinski@mchtr.pw.edu.pl 